\title{
Paraplegia
}

\section{Factors influencing the Regeneration of Axons in the Central Nervous System}

\author{
J. W. Fawcett
}

Physiological laboratory, Downing Street, Cambridge CB2 3EG, UK.

\begin{abstract}
Summary
Damage to the central nervous system (CNS) causes damage to neurons. This damage can result in the complete death of neurons, or in them becoming disconnected from their inputs or target structures due to disruption of axons. The main reason why damage to the human CNS is so disastrous and disabling is that axons will not in general regenerate in the mammalian brain, and neurons once lost are not replaced. In order, therefore, to repair the CNS, techniques will have to be developed to replace dead neurons, and induce axon regrowth. Central to the technologies necessary for brain repair is the ability to induce and control the growth of axons, since in a damaged brain both surviving and newly implanted neurons must grow axons to make or remake appropriate synaptic connections. Worthwhile treatments, however, do not necessarily require the repair of all the damaged circuits in the CNS, it may be possible to substantially improve the function of patients with relatively few reconnected axons, if those axons are ones which mediate particularly important behaviours, such as respiration, bladder control, or hand and arm movements.
\end{abstract}

Key words: Axon regeneration; Glia; Astroglia; Oligodendrocyte; Schwann cell.

\section{General considerations}

Invertebrates and lower vertebrates are quite able to regenerate axons in their CNS. If the brain or spinal cord of a fish or axolotl is damaged, the cut axons will begin to regenerate within a few days, will regrow back to their original targets and will form functional connections there: not only will axons regenerate, they show great accuracy in their ability to find and remake appropriate connections with their original target..$^{1-4}$ This ability has been gradually lost during evolution, and in mammals is almost completely absent. Frogs are at an intermediate stage, being able to regenerate axons in their optic nerves, but not in most of the rest of their $\mathrm{CNS} ;{ }^{5}$ regeneration in the optic nerve may have been preserved because it is still a developing structure, new retinal ganglion cells being born throughout the life of 
an animal, and producing axons which have to grow through the optic nerve to the brain. ${ }^{6,7}$ Why have we lost this useful repair function? One specific reason may be due to evolutionary changes in the properties of oligodendrocytes, but in general it is interesting and possibly significant that the loss of regeneration in the CNS in the vertebrates coincides with the loss of the ability to regenerate other body parts. Axolotls, for instance, will regenerate whole limbs if they are removed as well as axons in the CNS. ${ }^{8,9}$ Adult frogs, however, cannot regenerate limbs, and neither can they regenerate most of the axons of their CNS, although tadpoles can do both. The ability to regenerate cannot be of much evolutionary benefit, so it is theoretically possible that some chance genetic change could have led to its loss. It is also conceivable that some benefit accrues from restricting the regenerative ability of animals, although it is hard to see quite what that benefit might be. However, when one starts to look at the reasons why axons will not regenerate, and why limbs will not regrow, it is hard to discern any single basic cellular function whose loss might be responsible for the lack of regenerative ability. Indeed, when one examines the reasons for the failure of axon regeneration in the CNS, there seem to be three, apparently disconnected mechanisms which are responsible. These are: (1) the decrease in the vigour of axon growth from neurons as they become mature; (2) the inhibitory nature of oligodendrocytes and (3) the relative impenetrability of astrocytic tissues.

\section{Developmental changes in the vigour of axon growth and regeneration}

The neuron usually goes through two main phases in its existence. First it has to migrate to its correct position, and produce an axon which has to grow accurately through the complex terrain of the developing nervous system to form the right connections. If the neuron lives through the crisis of neuronal cell death, it then settles down to a second very different function, that of processing and transmitting information. This second phase does not call for axon growth in the sense of active elongation led by a growth cone, although the axon may have to stretch as the organism grows. All that is normally required is some ability to form and retract connections at the target neurons, in order to subserve the processes of neuronal plasticity. To some extent each neuron seems to possess a programme which tells it how far its axons need to grow during development. This is reflected both in rate of axonal growth, and in the actual length of processes. Thus if a variety of neurons are removed from an embryo during their normal period of axon growth, and are then examined in tissue culture, their rate of axon outgrowth correlates well with the distance between the neuron and its normal target. ${ }^{10}$ That there is a programme which determines length of outgrowth is shown by cross species transplant experiments, in which neurons from large animals (humans) are implanted into smaller ones (rats). Embryonic human striatal neurons have been implanted into adult rats, and grow their axons for a very much greater distance than the equivalent embryonic rat cells implanted into the same site. ${ }^{11}$ In view of the developmental changes in neuronal function which come with maturity, and the finishing of the normal axonal growth programme, it is perhaps surprising that any adult axons are able to regenerate, but in fact more or less all axons do retain some regenerative ability into adulthood. However, regeneration from adult neurons is very much less vigorous than axon outgrowth from the same neurons examined 
during development. The best demonstration of this in vivo again comes from transplant experiments. Transplants of many types of embryonic neurons into favourable sites in an adult brain can make extensive connections with the host, axons from the transplant growing for considerable distances. Transplants of adult or even early post-natal brain are generally much less successful, because most of the neurons die, and because those few that survive do not generally grow axons. ${ }^{12}$ The same pattern is seen if one examines the reciprocal connections, from host brain to transplant. Embryonic transplants into early post-natal brain may receive extensive axonal connections from the host, while transplants into adult animals are much less well innervated by host axons. ${ }^{13}$ Similar observations can be made in a sort of in vivo tissue culture model, where neuronal tissue is explanted into the anterior chamber of the eye. Again, embryonic neurons grow axons extensively into the iris, while older neurons, although they survive in this site, grow axons poorly. ${ }^{14}$ In tissue culture, the same sort of observations can be made. A tissue culture model of a glial scar is penetrated hardly at all by axons from postnatal neurons, but quite readily by axons from embryonic neurons. ${ }^{15}$ It is far from obvious what changes underlie this decline in axon growth. In some pathways regenerating axons have different cell surface adhesion molecules on their surface compared to developing ones, and these adhesion molecules may not be appropriate for the tissue surrounding the cut axon. ${ }^{16-18}$ There is also some evidence that the axonal cytoskeleton in regenerating axons may differ from that in embryonic axons: the microtubule associated protein MAP $1 \mathrm{x}$, for instance, is expressed during embryogenesis but not in regeneration, and regenerating but not embryonic frog retinal axons grow in spirals, which is probably due to some cytoskeletal property. ${ }^{19,20}$ Most of the cytoskeletal genes expressed in development, however, are re-expressed during regeneration. ${ }^{21,22}$ In general, it seems likely that some neuronal genes are permanently turned off after the axon growth programme has run its course, and it may be impossible to turn these on again. However, the ability of neurons to regenerate their axons can be influenced by the same trophic factors that were needed to keep the neuron alive during development, even though they seem to have little function in the adult animal. ${ }^{23}$ It is possible that manipulation of the trophic factors surrounding a damaged neuron might be sufficient to revitalise its axon growth.

Much of the interest and research in the field of axon regeneration in recent years has focused on the role of the local environment in encouraging or inhibiting axon regeneration. This interest largely stems from important observations originally made by Tello and Cajal suggesting that the tissues of the CNS are in some way inhibitory to axon growth. ${ }^{24}$ These observations led to Aquayo and his colleagues doing the now classic experiments, which confirmed that CNS tissue is inhibitory, and led to the conclusion that essentially all axons can regenerate, given a permissive environment in which to do so. ${ }^{25}$ By transplanting peripheral nervous system (PNS) tissue into the CNS, and CNS tissue into a peripheral nerve, they showed that almost all axons will regenerate in a peripheral nerve, but none will grow in CNS tissue. The inhibitory nature of CNS tissue can also be demonstrated by observing the regeneration of dorsal root ganglion axons towards the CNS in the dorsal root. If these axons are crushed in the dorsal root, which is PNS tissue containing Schwann cells, the axons will regenerate towards the CNS, but will stop growing as soon as they reach CNS tissue. ${ }^{26,27}$ The next step from these observa- 
tions was clearly to try and define exactly what features encourage axon regeneration in PNS tissue, and which features are inhibitory in CNS tissue.

In the PNS the critical cell type is the Schwann cell: if Schwann cells are removed from or excluded from the region where axons are trying to regenerate, there is no growth. ${ }^{28}$ On the Schwann cell there are a number of adhesion molecules with which growing axons interact, particularly $\mathrm{N}$-Cadherin and L1/NgCAM/ NILE. In addition, there is a basal lamina sheath surrounding the Schwann cell, containing laminin, collagen and fibronectin, all of which are good substrates for axon growth. ${ }^{29}$ In addition to providing optimal adhesive interactions with regenerating axons, Schwann cells in damaged nerves secrete nerve growth factor (NGF) and make NGF receptors, both of which may aid regeneration. ${ }^{30,31}$

If the reasons why PNS tissue is permissive to axon growth are reasonably well understood, the cause of CNS inhibition are less so, although there have been major advances in recent years. When a region of the CNS is damaged there is immediate death of cells in the damaged area, and axons passing through this region are cut. The axons distal to the cut degenerate, as does their myelin, and this debris is slowly removed by microglia. Astrocytes in and around the damaged area become reactive, undergoing cell division, increases in content of cytoskeletal material, and leading to a glial scar, so called because of its white scar-like appearance macroscopically. The glial scar eventually consists of many fine, closely apposed, interweaving astrocytic processes, interspersed with varying number of oligodendrocytes. The environment which surrounds an axon trying to regenerate in the CNS therefore varies with time. Initially there is much axonal and other debris, and in white matter degenerating myelin. Later, the environment is some form of glial scar. Since regeneration does not succeed at any time, one must look for cell types which are present throughout to provide the inhibition of growth, and these are astrocytes and oligodendrocytes. A number of groups have therefore looked at the interactions of these cell types with axons.

The results of studying axon-oligodendrocyte interactions in tissue culture are fairly straightforward; most axon growth cones are inhibited by oligodendrocytes. Starting from this observation two inhibitory molecules have been identified, ${ }^{32-34}$ blocking of which by antibodies leads to an increase in regeneration of axons in vivo. ${ }^{35,36}$ This important work is described in detail elsewhere in this volume. It is not possible, however, to provide an absolutely complete explanation of the inhibitory nature of the CNS environment entirely on the basis of the inhibitory effects of oligodendrocytes, although this is clearly an important contributor to the failure of regeneration. There is a substantial body of evidence which indicates that astrocytes may also be inhibitory to the regeneration of axons.

Many investigators over the years have studied the ultrastructural appearance of the damaged CNS, and looked at the tips of axons failing to regenerate. In general these axon tips are in contact with astrocytic processes. Axon tips in contact with axons are quite different in appearance to axons that have got stuck in scar tissue in a peripheral neuroma: in the peripheral neuroma the axons are swollen and bloated with cytoskeletal material, vesicles and other membranous organelles, while axons in contact with astrocytes look as if they have received a normal physiological stop signal, and are trying to form synapses: the axon endings are not swollen, do not contain much cytoskeletal material, and may even contain structures that look like synaptic vesicles. ${ }^{26}$ There is also evidence that tissues composed primarily of astro- 
cytes can block the regeneration of axons. Glial scars in the CNS may contain very few oligodendrocytes, yet axons will not penetrate them, and such glial scars can be transplanted into peripheral nerves, where they will block the regrowth of PNS axons. ${ }^{37}$ Optic nerves which are free of oligodendrocytes, either because they are transplanted from late embryonic animals which have not yet developed oligodendrocytes, or because they come from the mutant oligodendrocyte deficient rat, are still not very conducive to axonal regeneration. ${ }^{38-40}$ Despite the weight of in vivo evidence that astrocytic tissues can block axon regeneration, it has proven hard to reproduce this inhibition in vitro, indeed monolayer cultures of astrocytes provide a particularly advantageous surface for the growth of axons from most neurons. ${ }^{41,42}$ Recently, however, we have developed a method for culturing astrocytes as a more lifelike three-dimensional tissue, and this tissue is not penetrated by axons regenerating from post-natal neurons, although the more vigourous axons from the embryonic neurons are able to do so. ${ }^{15}$ Astrocytic tissues are clearly inhibitory to axon growth, but the mechanism by which they are inhibitory is less clear, although there are some clues. Astrocytes, like oligodendrocytes, produce molecules which are inhibitory to axon growth cones, although the actual molecules are different, ${ }^{43}$ the astrocytic growth cone collapsing activity probably being due to the same molecules which exclude axons from the posterior half of each embryonic somite. ${ }^{44}$ There is also evidence obtained by placing neurons onto sections of brain in vitro, that the glial scar surrounding an area of CNS damage produces substances which are inhibitory to axon growth, ${ }^{45}$ although David et al., doing much the same experiment, report the opposite. ${ }^{46}$ Another possible mechanism for the inhibitory effect of astrocytic tissues centres on the proteases and protease inhibitors secreted by many cells. Invasive malignant tumour cells secrete large quantities of proteases, and if these are blocked the cells cease to be invasive. ${ }^{47}$ Static tissues, such as astrocytes, secrete a preponderance of protease inhibitors. ${ }^{48}$ Axon growth cones are a specialised form of invasive cell process, and also secrete proteases. $^{49}$ If one class of these, the serine proteases, are inhibited, then the growth of axons from embryonic neurons into astrocytic tissue is also considerably reduced. ${ }^{50}$ If the inhibitory effect of astrocytes is to be removed, then, it will be necessary to develop means of blocking the inhibitory molecules they produce, of adjusting the balance between proteases and protease inhibitors in their vicinity, and perhaps of making astrocytic tissues less dense by decreasing intercellular adhesion.

There appear to be three main reasons why axons will not regrow in the CNS; the inhibitory factors on the surface of oligodendrocytes, the relative impenetrability of astrocytes, and the declining vigour of axon regeneration with age. This leads to the practical question of how many of these factors will have to be dealt with before axon regeneration in the CNS becomes a reality. Present evidence suggests that it is not sufficient just to remove one type of inhibition. The inhibitory effect of oligodendrocytes has been neutralised in animals by treating them with antibodies which block the two inhibitory molecules, and these animals exhibit considerably more regeneration than normal when the spinal cord is lesioned, but not enough to restore lost function. ${ }^{36}$ Replacement of adult neurons with embryonic ones also helps, but is not in itself sufficient. If embryonic neurons are placed in the adult brain, their axons grow very much more than the equivalent adult neurons, but they are still not able to cross significant distances to an appropriate 
target area; they only grow when the neurons are transplanted within a region of target neurons. ${ }^{12}$ At present there is no way of making it easy for axons to penetrate astrocytes, so the effects of removing this inhibitory factor by itself are not known. If more than one inhibitory effect must be eliminated, must it be all three, or is it enough to eliminate two? When a peripheral nerve graft is inserted into the CNS, the inhibitory influences of both astrocytes and oligodendrocytes are removed. The result is that mature neurons can regenerate their axons well within the Schwann cell environment, suggesting that removal of the two glial effects may in itself be sufficient. ${ }^{25}$ Similarly, it is conceivable that the combination of embryonic neurons and removal of just one of the glial inhibitory effects might lead to successful axon growth. It is possible, therefore, that a combination of two treatments might be sufficient to greatly enhance the repair processes in the CNS following injury.

\section{References}

I Davis BM, Ayers JL, Koran L, Carlson J, Anderson MC, Simpson SB Jr. Time course of salamander spinal cord regeneration and recovery of swimming: HRP retrograde pathway tracing and kinematic analysis. Exp Neurol 1990: 108:198-213.

2 Gaze RM, Jacobson M. A study of the retinotectal projection during regeneration of the optic nerve in the frog. Proc R Soc Lond (Biol) 1963: 157:420-448.

3 Sperry RW. Chemoaffinity in the orderly growth of nerve fiber patterns and connections. Proc Natn Acad Sci USA 1963: 50:703-709.

4 Attardi DG, Sperry RW. Preferential selection of central pathways by regenerating optic fibers. Exp Neurol 1963: 7:46-64.

5 Lyon MJ, Stelzner DJ. Tests of the regenerative capacity of tectal efferent axons in the frog, Rana pipiens. J Comp Neurol 1987: 255:511-525.

6 Gaze RM, Keating MJ, Ostberg A, Chung SH. The relationship between retinal and tectal growth in larval Xenopus. Implications for the development of the retinotectal projection. J Embryol Exp Morph 1979: 53:103-143.

7 Beach DB, Jacobson M. Patterns of cell proliferation in the retina of the clawed frog during development. J Comp Neurol 1979: 183:603-614.

8 Brockes JP, Kintner CR. Glial growth factor and nerve-dependent proliferation in the regeneration blastema of Urodele amphibians. Cell 1986: 45:301-306.

9 Keeble S, Maden $M$. The relationship among retinoid structure, affinity for retinoic acid-binding protein, and ability to respecify pattern in the regenerating axolotl limb. Dev Biol 1989: 132:26-34.

10 Davies AM. Intrinsic differences in the growth rate of early nerve fibres related to target distance. Nature 1989: 337:553-555.

11 Wictorin K, Brundin P, Gustavii b, Lindvall O, Björklund A. Reformation of long axon pathways in adult rat central nervous system by human forebrain neuroblasts. Nature 1990: 347:556-558.

12 Bjorklund A, Stenevi U. Intracerebral neural implants: neuronal replacement and reconstruction of damaged circuitries. Ann Rev Neurosci 1984: 7:279-308.

13 McLoon SC, Lund RD. Development of fetal retina, tectum, and cortex transplanted to the superior colliculus of adult rats. J Comp Neurol 1983: 217:376-389.

14 Sieger A, Olson L. Quantitation of fiber growth in transplanted central monoamine neurons. Cell Tissue Res 1977: 179:285-316.

15 Fawcett JW, Housden E, Smith-Thomas L, Meyer RL. The growth of axons in three dimensional astrocyte cultures. Dev Biol 1989: 135:449-458.

16 Cohen J, Burne JF, McKinlay C, Winter J. The role of laminin and the laminin/fibronectin receptor complex in the outgrowth of retinal ganglion cell axons. Dev Biol 1987: 122:407-418.

17 Hall DE, Neugebauer KM, Reichhardt LF. Embryonic neural retinal cell response to extracellular matrix proteins: developmental changes and effects of the cell substratum attachment antibody (CSAT). J Cell Biol 1987: 104:623-634.

18 Grant P, Tseng Y. Embryonic and regenerating Xenopus retinal fibers are intrinsically different. Dev Biol 1986: 114:475-491.

19 Grant P, Tseng Y. In vitro growth properties of Xenopus retinal neurons undergo developmental modulation. Dev Biol 1989: 133:502-514.

20 Woodhams PL, Calvert R, Dunnett SB. Monoclonal antibody G10 against microtubule-associated protein $1 \mathrm{x}$ distinguishes between growing and regenerating axons. Neuroscience 1989: 28:49-59.

21 Miller FD, Tetzlaff W, Bisby MA, Fawcett JW, Milner RJ. Rapid induction of the major 
embryonic alpha-tubulin mRNA, T alpha 1, during nerve regeneration in adult rats. J Neurosci 1989: 9:1452-1463.

22 Hoffman PN, Cleveland DW. Neurofilament and tubulin expression recapitulates the development program during axonal regeneration: Induction of a specific beta-tubulin isotype. Proc Natl Acad Sci USA 1988: 85:4530-4533.

23 Lindsay RM. Nerve growth factors (NGF, BDNF) enhance axonal regeneration but are not required for survival of acult sensory neurons. J Neurosci 1988: 8:2394-2405.

24 Cajal S. Ramon. In: May RM, (ed.) Degeneration and Regeneration of the Nervous System. Oxford: Oxford University Press, 1928.

25 David S, Aguayo AJ. Axonal elongation into peripheral nervous system bridges after central nervous system injury in adult rats. Science 1981: 241:931-933.

26 Liuzzi FJ, Lasek RJ. Astrocytes block axonal regeneration in mammals by activating the physiological stop pathway. Science 1987: 237:642-645.

27 Carlstedt T, Dalsgaard CJ, Molander C. Regrowth of lesioned dorsal root nerve fibers into the spinal cord of neonatal rats. Neurosci Lett 1987: 74:14-18.

28 Hall SM. The effect of inhibiting Schwann cell mitosis on the re-innervation of acellular autografts in the peripheral nervous system of the mouse. Neuropathol Appl Neurobiol 1986: 12:401-414.

29 Bixby JL, Lilien J, Reichhardt LF. Identification of the major proteins that promote neuronal process outgrowth on Schwann cells in vitro. J Cell Biol 1988: 107:353-361.

30 Taniuchi M, Clark HB, Johnson EMJR. Induction of nerve growth factor receptor in Schwann cells after axotomy. Proc Natl Acad Sci USA 1986: 83:4094-4098.

31 Heumann R, Korsching S, Bandtlow C, Thoenen H. Changes of nerve growth factor synthesis in nonneuronal cells in response to sciatic nerve transection. J Cell Biol 1987: 104:1623-1631.

32 Caroni P, Schwab ME. Two membrane protein fractions from rat central myelin with inhibitory properties for neurite growth and fibroblast spreading. J Cell Biol 1988: 106:1281-1288.

33 Fawcett JW, Rokos J, Bakst I. Oligodendrocytes repel axons and cause axonal growth cone collapse. J Cell Sci 1989: 92:93-100.

34 Bandtlow C, Zachleder T, Schwab ME. Oligodendrocytes arrest neurite growth by contact inhibition. J Neurosci 1990: 10:3837-3848.

35 Caroni P, Schwab ME. Antibody against myelin associated inhibitor of neurite growth neutralizes nonpermissive substrate properties of CNS white matter. Neuron 1988: 1:85-96.

36 Schnell L, Schwab ME. Axonal regeneration in the rat spinal cord produced by an antibody against myelin-associated neurite growth inhibitors. Nature 1990: 343:269-272.

37 Reier PJ, Houle JD. The glial scar: its bearing on axonal elongation and transplantation approaches to CNS repair. Adv Neurol 1988: 47:87-138.

38 Giftochristos N, David S. Immature optic nerve glia of rat do not promote axonal regeneration when transplanted into a peripheral nerve. Brain Res 1988: 467:149-153.

39 Marciano FF, Gocht A, Dentinger MP, Hof L, Csiza CK, Barron KD. Axonal regrowth in the amyelinated optic nerve of the myelin-deficient rat: Ultrastructural observations and effects of ganglioside administration. J Comp Neurol 1990: 295:219-234.

40 Berry M, Hall S, Follows R, Wyse JPH. Defective myelination in the optic nerve of the Browman-Wyse (BW) mutant rat. J Neurocytol 1989: 18:141-159.

41 Noble M, Fok-Seang J, Cohen J. Glia are a unique substrate for the in vitro growth of central nervous system neurons. J Neurosci 1984: 4:1892-1903.

42 Tomaselli KJ, Neugebauer KM, Bixby J, Lilien J, Reichardt LF. N-Cadherin and Integrins: Two receptor systems that mediate neuronal process outgrowth on astrocyte surfaces. Neuron 1988: $1: 33-43$.

43 Keynes RJ, Johnson AR, Picart CJ, Cook GMW, Dunn-Borkowski OM. A Glycoprotein fraction from adult chicken grey matter causes collapse of CNS and PNS growth cones in vitro. Soc Neurosci Abstr 1990: 16:169.

44 Davies JA, Cook GMW, Stern CD, Keynes RJ. Isolation from chick somites of a glycoprotein fraction that causes collapse of dorsal root ganglion growth cones. Neuron 1990: 4:11-20.

45 Rudge JS, Silver J. Inhibition of neurite outgrowth on astroglial scars in vitro. J Neurosci 1990: 10:3594-3603.

46 David S, Bouchard C, Tsatas O, Giftochristos N. Macrophages can modify the nonpermissive nature of the adult mammalian central nervous system. Neuron 1990: 5:463-469.

47 Ossowski L. Plasminogen activator dependent pathways in the dissemination of human tumor cells in the chick embryo. Cell 1988: 52:321-328.

48 Gloor S, Odink K, Guenther J, Nick H, Monard D. A glia-derived neurite promoting factor with protease inhibitory activity belongs to the protease nexins. Cell 1986: 47:687-693.

49 Pittman RN, Patterson PH. Characterization of an inhibitor of neuronal plasminogen activator released by heart cells. J Neurosci 1987: 7:2664-2673.

50 Fawcett JW, Housden E. The effects of protease inhibitors on axon growth through astrocytes. Development 1990: 109:59-66. 